\title{
THE SYSTEM FOR COMPLEX MAGNETIC SUSCEPTIBILITY MEASUREMENT OF NANOPARTICLES WITH 3D PRINTED CARCASS FOR INTEGRATED RECEIVE COILS
}

\author{
Mateusz Midura, Przemysław Wróblewski, Damian Wanta, Grzegorz Domański, Mateusz Stosio, \\ Jacek Kryszyn, Waldemar T. Smolik \\ Warsaw University of Technology, Faculty of Electronics and Information Technology, Institute of Radioelectronics and Multimedia Technology, \\ Division of Medical and Nuclear Electronics, Warsaw, Poland
}

\begin{abstract}
The article concerns the research on the properties of core-shell superparamagnetic nanoparticles in the context of their use in medicine for diagnostics and therapy. The article presents a system for impedance (AC) spectroscopy of nanoparticles with a new arrangement of receive coils. A significant modification was the position of the reference coil in relation to the receive coils as well as the method of winding and routing the wires on the carcass. The $3 D$ printing technique was used in the production of the measuring coil system. The aim of the work was to experimentally verify the developed measurement system and analyze its properties. The system tests were carried out at low frequencies ranging from 2 to $50 \mathrm{kHz}$. Complex magnetic susceptibility was measured for superparamagnetic iron oxide nanoparticles in polymer shells in a physiological saline solution. The obtained results confirmed the relevance of the concept of the measurements. In summary, the observed properties of the realized system are discussed and further directions of its development are proposed.
\end{abstract}

Keywords: superparamagnetic nanoparticles, magnetic particle spectroscopy, magnetic susceptibility, hyperthermia

\section{SYSTEM DO POMIARU ZESPOLONEJ PODATNOŚCI MAGNETYCZNEJ NANOCZĄSTEK Z WYKONANYM W TECHNOLOGII DRUKU 3D KARKASEM ZINTEGROWANYCH CEWEK ODBIORCZYCH}

\begin{abstract}
Streszczenie. Artykut dotyczy badań właściwości nanocząstek superparamagnetycznych typu rdzeń-powłoka w kontekście wykorzystania ich w medycynie do diagnostyki jak $i$ terapii. W artykule przedstawiono układ do spektroskopii impedancyjnej (AC) nanoczastek z nowym uktadem cewek odbiorczych. Istotna modyfikacją byla pozycja cewki referencyjnej względem cewek odbiorczych jak również sposób nawijania i prowadzenia przewodów na karkasie. $W$ realizacji uktadu cewek pomiarowych wykorzystana została technika druku 3D. Celem pracy byta eksperymentalna weryfikacja op racowanego układu pomiarowego i analiza jego wtasności. Testy uktadu zostaty przeprowadzone dla niskich czestotliwości w zakresie od 2 do 50 kHz. Pomiary zespolonej podatności magnetycznej dokonano dla nanoczastek superparamagnetycznych tlenku żelaza $w$ otoczkach polimerowych $w$ roztworze soli fizjologicznej. Uzyskane wyniki potwierdziły poprawność koncepcji realizacji pomiarów. W podsumowaniu omówiono zaobserwowane własności zrealizowanego układu i zaproponowano dalsze kierunki jego rozwoju.
\end{abstract}

Słowa kluczowe: nanocząstki superparamagnetyczne, spektroskopia cząstek magnetycznych, podatność magnetyczna, hipertermia

\section{Introduction}

The extensive application of magnetic nanoparticles has attracted a great attention to their measurable properties. The potential wide application of magnetic nanoparticles has attracted a lot of attention from researchers representing various fields of science and has resulted in great interest in measurement methods that enable their characterization.

In medicine, magnetic nanoparticles are applied in diagnostics as well as in therapy, e.g. as a tracer in magnetic particle imaging (MPI) or carriers in drug delivery and in microfluidic devices [8] or as a heating medium in hyperthermia.

Magnetic nanoparticles may have different morphology but typically, those used in hyperthermia, are composed of superparamagnetic iron core and biocompatible coating (shell). The shell layer around a functional nanoparticle core provides a possibility to modify their physical and chemical properties, and allows binding of specific ligands such as drug molecules. One of the magnetic properties of the core that characterises nanoparticles is complex magnetic susceptibility. Imaginary part of susceptibility corresponds to magnetic losses generated due to alternating magnetic field.

In magnetic hyperthermia [4, 16] as well as in magnetic particle imaging it is crucial to determine the optimal frequency at which extreme values of power loss are obtained. In the first application, magnetic losses of nanoparticles should be maximized in the tumour volume, whereas at the same time losses generated due to Eddy currents in patient's body should be as low as possible. In MPI any magnetic losses causing undesired heating of the body should be reduced to minimum.

Significant research problem is to model nanoparticle properties and develop measurement method dedicated to specific applications. In magnetic hyperthermia the magnetic loss is critical parameter directly connected with an ability to generate heat. It strictly depends on hydrodynamic diameter $(\mathrm{Dh})$, which is difficult to measure directly. The only method for direct Dh evaluation is Dynamic Light Scattering (DLS) [9]. The geometric sizes of the produced nanoparticles vary in the range from $5 \mathrm{~nm}$ to $100 \mathrm{~nm}$ (core diameter). Frequently, the value declared by the manufacturers is approximate and does not include particle's diameter dispersion.

Although several techniques for the synthesis of metal-based core-shell nanoparticles are known, the production of MNPs with well controlled magnetic parameters remains a challenge. A knowledge of the accurate hydrodynamic diameter is necessary for correct modelling of magnetization. It is well known that following factors affect the magnetic susceptibility: the hydrodynamic diameter, the diameter of the metallic core and biocompatible coating, the shape and the material of the core and the shell, as well as the medium in which the nanoparticles are dispersed.

Magnetic properties of nanoparticles can be measured in an immobilize state or as a liquid suspension. These properties differ greatly depending on the environment which determines the degree of mobility. Although, results for immobilized particles are highly dependent on immobilization procedure, they have been quite well documented [1]. Whereas the measurement of magnetic particle suspension still needs standardization and better models for interpretation of the results. There is a need to develop robust method for measuring complex magnetic susceptibility of MNPs which is critical in assessing the effectivity and safety in medical applications.

Magnetic Particle Spectroscopy (MPS) is commonly used for determination of nanoparticle properties like hydrodynamic diameter distribution or magnetic core diameter [14]. These parameters are necessary for calculating complex magnetization of an investigated sample. However, there are also another methods such as Nuclear Magnetic Resonance (NMR) [15] 
or Transmission Electron Microscopy (TEM) that allow to evaluate nanoparticle properties [9]. MPS was successfully applied to verify theoretical models of magnetization $[3,7]$.

A commonly used devices to measure magnetic properties of nanoparticles are: Vibrating-Sample Magnetometer (VSM) [11], Magnetic Particle Spectroscope (MPS) [2, 10, 18], Superparamagnetic quantifier (SpaQ) [6] and $\mathrm{AC}$ magnetometer [13].

In VSM method higher magnetic fields cause the saturation of examined nanoparticles and thereby their magnetic moment remains constant. It is also a well-known fact that VSM measurements at low fields cause problems of magnetic remanence in the system when superconducting coils (SQUID) are used [20].

In a SPaQ a small AC field is combined with a gradual DC offset. It analyses only the fundamental frequency of the detection signal whereas MPS measures the whole harmonic spectrum caused by the nonlinearity of the magnetization. MPS can be described as a dynamic measurement of the magnetization curve compared to the VSM or SPaQ. Both the SpaQ and MPS can be conducted at room temperature, provide accurate measurements of the magnetization curve, and both are superior to VSM especially at low amplitudes of magnetisation field [6].

Whereas all these methods use typically a single excitation frequency, AC magnetometer (impedance spectroscopy) applies multitude of frequencies to obtain spectral magnetic response of a sample. Most bench-top systems are able to analyse only small sample quantities due to the requirements of strong magnetic field. A miniaturized measurement system for AC magnetometry was also developed as it was presented in a project by Šouc et al. [12]. The effort is made to improve sensitivity, signal purity and measurement accuracy.

In this paper, we verify a laboratory setup for measurement of complex magnetic susceptibility by AC impedance spectroscopy method. For this purpose, the system for measuring complex magnetic susceptibility in function of frequency was created. The novelty of the elaborated experimental setup lies in a symmetrical placement of a reference coil positioned in equal distance between two detection coils. The applied 3D-printing technology allowed to fabricate custom-designed carcass for proposed arrangement of coils and ensured proper fitting of carcass in the excitation coil.

\section{Methodology}

\subsection{System configuration}

Laboratory setup for impedance spectroscopy is composed of a transmit circuit for generating the sinusoidal magnetic excitation field and a receiving circuit for detecting the MNP response in the form of non-sinusoidal magnetization. To obtain high value of an exciting magnetic field, a resonant circuit is used in the transmitting part of the system. The receiving circuit requires an application of a cancellation coil in pair with a detection coil to cancel the excitation signal in the receiving circuit. This way only the magnetization signal from MNPs located inside receiving coils is present in the detecting circuit. The amplitude and the phase of magnetization signal is measured using a phase-sensitive detector.

Schematic chart of the system used in measurements is shown in Fig. 1. Self-designed excitation coil is a part of resonant circuit. Different sets of capacitors were used to tune resonant frequency. Function generator connected to power amplifier was used as a signal source. Two receiving coils have been wound in the opposite directions and placed inside excitation coil. This configuration allows to cancel excitation signal generated due to the excitation field in receiving coils and was widely discussed in [12, 13, 19]. Therefore, all harmonic components of magnetization signal can be measured by the lock-in amplifier. Lock-in amplifier or phase-sensitive detector is quite a versatile measurement instrument for extracting low-level signals buried in noise [5].

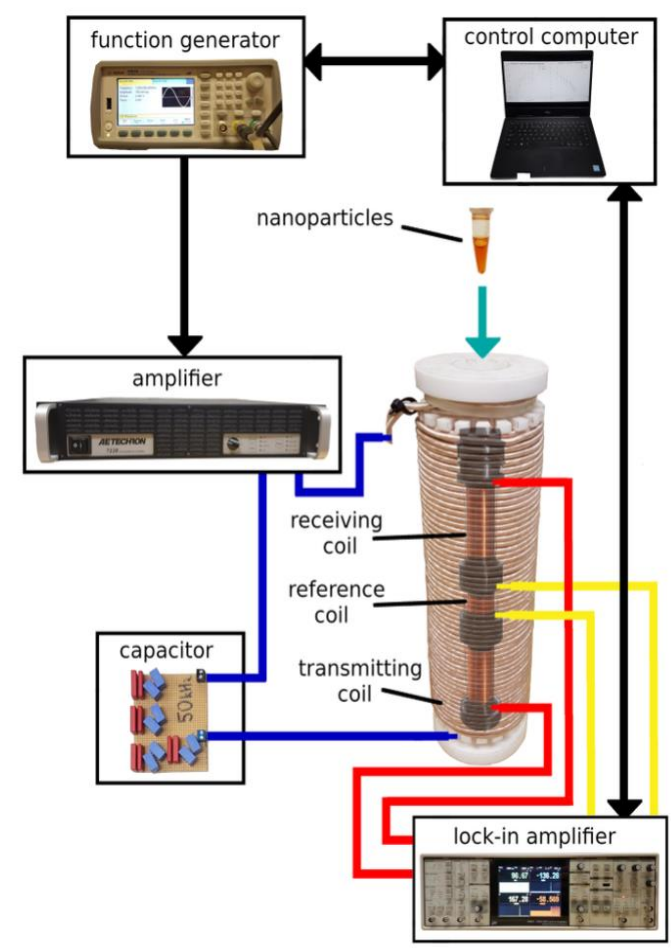

Fig. 1. Scheme of top-bench setup for impedance spectroscopy

\subsection{Excitation coil}

The transmit coil is a solenoid coil (length: $200 \mathrm{~mm}$, inner diameter: $30 \mathrm{~mm}$, outer diameter $60 \mathrm{~mm}$, overall turns 220) (Fig. 2a). The bore in the carcass of excitation coil was designed to enable inserting the receiving coils together with the measured sample. Detailed design of excitation coil with the analysis of magnetic field distribution was presented in [17]. Litz wire was used in order to minimize skin effect, which cause reduction of current in excitation circuit for higher frequencies. The litz wire contains 7 bundles and each bundle is composed of 630 strands of $0.1 \mathrm{~mm}$ copper wire. To protect carcass from melting due to heat generated by excitation coil PTFE (Teflon) was used as a construction material. Active cooling of transmit coil was not necessary during the experiment. Electric parameters of designed coil are presented in Tab. 1. The skin effect was inevitable for frequencies higher than $30 \mathrm{kHz}$. Thus to maintain the constant amplitude of excitation magnetic field it was necessary to increase gain of the amplifier accordingly.

Table 1. Electric parameters of transmit coil

\begin{tabular}{|c|c|c|c|c|c|}
\hline $\begin{array}{c}\mathrm{L} \\
{[\mu \mathrm{H}]}\end{array}$ & $\begin{array}{c}\mathrm{R}(<25 \mathrm{kHz}) \\
{[\Omega]}\end{array}$ & $\mathrm{Q}(20 \mathrm{kHz})$ & $\begin{array}{c}\mathrm{Z}(<1 \mathrm{kHz}) \\
{[\Omega]}\end{array}$ & $\mathrm{N}$ & $\begin{array}{c}\mathrm{L} \\
{[\mathrm{mm}]}\end{array}$ \\
\hline 747.95 & 0.22 & 427 & $<5$ & 220 & 200 \\
\hline
\end{tabular}

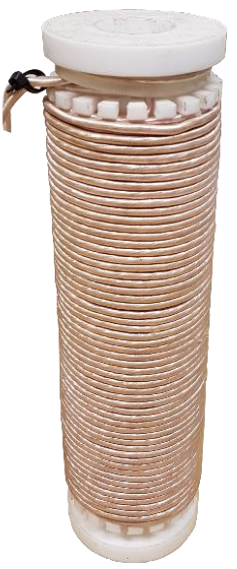

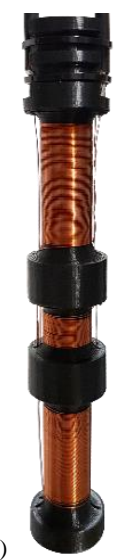

Fig. 2. Coils used in the measurement setup: a) transmit coil, b) receive coils 


\subsection{Receive and reference coils}

The receive coil system (Fig. 2b) is composed of two opposite wound serial coils: detection coil, cancelation coil and reference coil. Electric parameters of these coils are shown in Tab. 2.

Table 1. Electric parameters of receive coils

\begin{tabular}{|c|c|c|c|c|c|c|}
\hline Coil & $\begin{array}{c}\mathrm{L} \\
{[\mu \mathrm{H}]}\end{array}$ & $\begin{array}{c}\mathrm{R} \\
(<25 \mathrm{kHz}) \\
{[\Omega]}\end{array}$ & $\begin{array}{c}\mathrm{Q} \\
(20 \mathrm{kHz})\end{array}$ & $\begin{array}{c}\mathrm{Z} \\
(<1 \mathrm{kHz}) \\
{[\Omega]}\end{array}$ & $\mathrm{N}$ & $\begin{array}{c}1 \\
{[\mathrm{~mm}]}\end{array}$ \\
\hline Receive & 139.66 & 2.88 & 3.0 & 3.01 & 198 & 128.5 \\
\hline Detection & 74.3 & 1.44 & 3.2 & 1.52 & 99 & 34 \\
\hline Cancellation & 69.25 & 1.44 & 3.0 & 1.51 & 99 & 37 \\
\hline Reference & 13.60 & 0.6 & 1.6 & 0.6 & 28 & 10 \\
\hline
\end{tabular}

The detection coil serves for measurement of magnetization signal of nanoparticles whereas the main purpose of cancelation coil is to eliminate the induced signal by primary magnetic field.

Cancelation is achieved when signal from emptied receive coils is brought to minimum. This can be obtained by positioning the carcass inside the excitation coil using a linear actuator.

The reference coil is integrated with receive coils. That means it is placed inside an excitation coil's bore together with the receive coils on the same carcass. The reference coil measures excitation field signal that provide a frame of reference to lock-in amplifier. It also allows to estimate the strength of magnetic field, that can be used in feedback loop to control the amplitude of function generator signal.

In our design a significant modification was the position of the reference coil in relation to the receiving coils as well as the method of winding and routing the wires on the carcass. The 3D printing technique was used in the implementation of the measuring coil system.

Detection coils' support was designed and built using 3Dprinter. Both receive coils and reference coil were wound around 3D-printed carcass. The isolated copper wire of $0.6 \mathrm{~mm}$ was used Reference coil was placed in the gap between receiving. Induced voltage was used as a reference signal for lock-in detector.

The design of carcass was prepared using Autodesk Inventor Professional 2021 (Fig. 3). To minimize the mutual inductance between receiving and cancelling coils, both coils' supporting shafts with a length of $34.50 \mathrm{~mm}$ has been pulled apart at a distance of $59.50 \mathrm{~mm}$. The outer diameter of $29 \mathrm{~mm}$ has been chosen to fit bore diameter of excitation coil $(30 \mathrm{~mm})$. Arrangement of reference coil in the gap between detection coils required design of additional holes that served for the proper guiding of both reference coil and detection coils wires. Both ends of each cooper wire were twisted along the length of the cable to eliminate common interference induced by the primary excitation field. Two cable ties were used to ensure a firm, secure soldering and attachment of coaxial cable to $0.6 \mathrm{~mm}$ copper wires. For this purpose two troughs were designed to accommodate the flexible tape and the head of cable ties. The upper inlet was adjusted for the size of test tube's cup. It allowed a repeatable stable placement of samples during experiment. At the bottom of carcass the hole was left for inserting a manually controlled linear actuator that was used for calibration.

Using measurement setup with novel arrangement of reference coil for given frequency we were able to maintain constant phase shift between reference and detection coil. Using 3D-printing method for carcass construction significant resemblance in geometric properties of both detection and cancelling coil has been achieved. It allowed to reduce the unbalanced sinusoidal signal induced in receiving coils to approximately $5 \mathrm{mV}$. As we expected, the placement of reference coil did not impair cancellation of excitation signal in receiving coils.
The designed carcass was printed on Ultimaker S3 3D-printer with Polylactic acid (PLA Tough) used as a construction material. Grid pattern infill of $20 \%$ has been set (Fig. 4). The printer was equipped with $0.25 \mathrm{AA}$ nozzle. Adhesion plate was added. No secondary support material was provided because none support was needed. The printing lasted 6 hours.

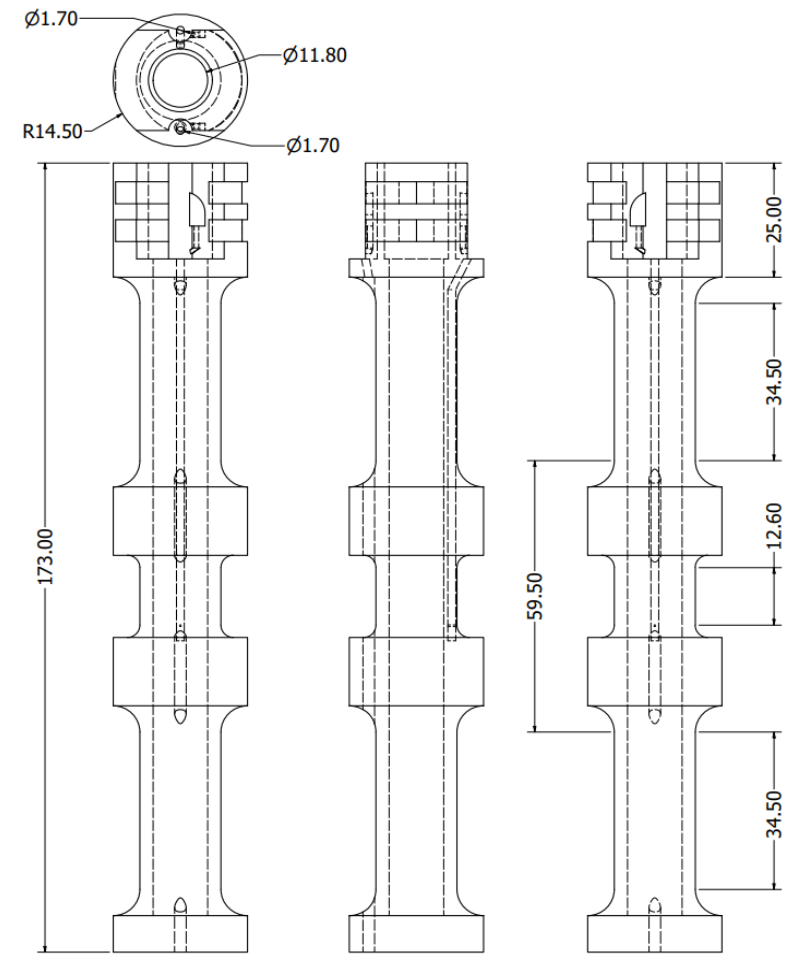

Fig. 3. Technical drawing of carcass designed in Autodesk Inventor Professional 2021. Four projections of the model with marked chosen dimensions on

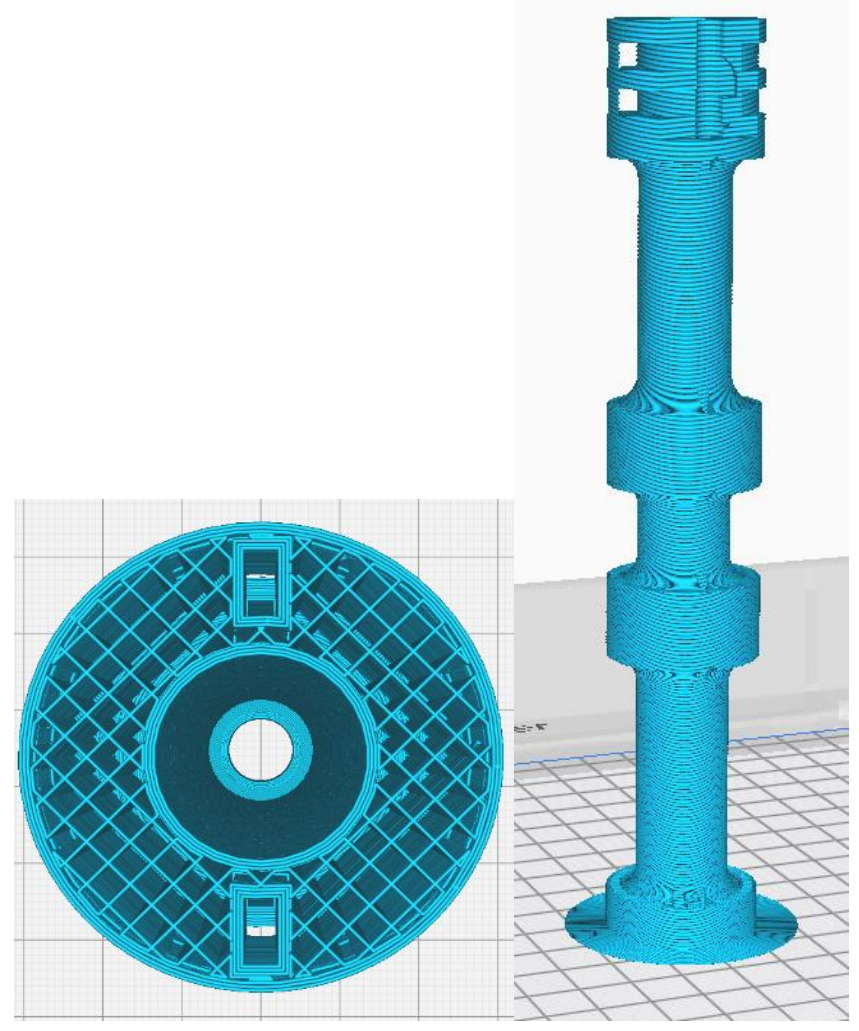

Fig. 4. 3D-view of designed receive coils carcass from Ultimaker Cura - software for setting $3 D$ printing parameters. Infill grid pattern is visible in the cross-section (on the left). Carcass model divided into printable layers (on the right) 


\subsection{Sample preparation}

Samples were prepared using $20 \mathrm{~nm}$ iron oxide nanoparticles nanomag-D-spio (Micromod). Dextran iron oxide composite particles were originally dissolved in water. Two samples containing $1 \mathrm{ml}$ of nanoparticle suspension were prepared (10 $\mathrm{mm}$ diameter and $17 \mathrm{~mm}$ height). The first specimen contained original iron concentration of $2.4 \mathrm{mg} / \mathrm{ml}$ as given by the manufacturer. The second one was diluted with demineralised water to $0.5 \mathrm{mg} / \mathrm{ml}$. However, this value should be considered as a rough approximation due to the limited accuracy of the syringe used for drawing the nanoparticle suspension and the diluent. Both samples were measured at room temperature.

\subsection{Experimental procedure}

The measurement was performed for nine different frequencies, ranging from 2 to $50 \mathrm{kHz}$ using lock-in amplifier.

After assembling the resonant circuit for desired excitation frequency, the signal from the function generator was triggered. Receiving coil system was inserted inside the excitation coil. Empty probe signal was minimized by precise positioning of detection coils in relation to primary excitation field using a manually controlled linear actuator. The procedure had to be repeated for each frequency because the position of minimum differs slightly with frequency. A control measurement of remaining unbalanced signal of empty probe was performed. The signal of reference coil was fed to reference input of lock-in amplifier.

A test tube with nanoparticle solution was then inserted inside the detection coil. The complex magnetization signal of the nanoparticles was measured. The next test tube with the different sample was inserted and a second measurement was performed. Then the resonant circuit had been assembled for next frequency and so the whole procedure was being repeated until all results were collected.

\section{Results}

\subsection{Assessment of constructed coils}

To ensure proper functioning of the system the uniformity of magnetic field generated by excitation coil and sensitivity of receive coils was assessed. Uniformity was measured using self-made probing coil connected to an oscilloscope. Results were

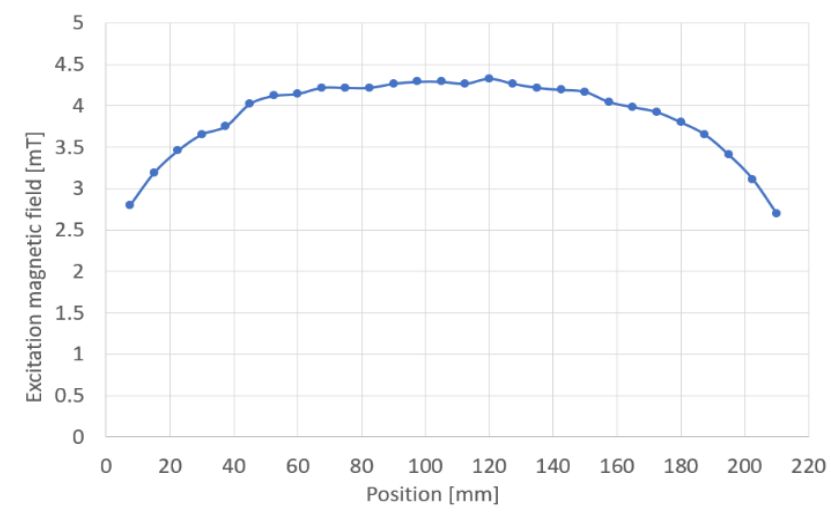

Fig. 5. Spatial distribution of magnetic field amplitude along Z-axis of the excitation coil presented in Fig. 5. The amplitude of the AC magnetic field at $15 \mathrm{kHz}$ was $4.25 \mathrm{mT}$ measured at the centre of excitation coil. Max deviation of uniformity of the magnetic field in the bore of coil was $6.5 \%$ at distance of inner $13 \mathrm{~cm}$ that corresponds with the length of working volume of receive coils.

Sensitivity was evaluated using thin magnetic sample driven by excitation magnetic field $(f=15 \mathrm{kHz}, \quad \mathrm{B}=4.25 \mathrm{mT})$ and measuring the response signal using receiving coils and the oscilloscope. Results were presented in Fig. 6. The peek value of induced voltage in receive coils differs slightly due to imperfect winding. The receive coils have different winding density - the same number of turns at different lengths (Tab. 2). That results in a remaining unbalanced sinusoidal signal induced in detection coils to less than $3 \mathrm{mV}$ noise level.

\subsection{Magnetic susceptibility measurements}

The measurements of complex magnetic susceptibility of prepared samples were performed in frequency range of $2.2-50 \mathrm{kHz}$. The real and imaginary parts of susceptibility were presented in Fig. 7 and Fig. 8 respectively. In-phase magnetic susceptibility value decreases rapidly at low frequencies and significantly slower above $3.3 \mathrm{kHz}$. On the contrary, out-of-phase magnetic susceptibility grows slowly as frequency increases. Maximum value of out-of-phase component is expected to occur at higher frequencies beyond the range of the experiment where the Brown relaxation can be observed. Nanoparticle concentration in both examined samples had no influence on the shape of magnetic susceptibility function. Iron concentration ratio in examined samples was one to five. However, the ratio of measured magnetic susceptibility values between samples was 3.3 for real part and 3.7 for imaginary component.

Noise in the measured signal was at level of $10 \mathrm{nV}$ but it was not the main factor influencing the measurement uncertainty. When the experiment was repeated, we observed a deterministic error probably caused by changing environmental circumstances (e.g. thermal instability of measuring circuit or high vulnerability to cable displacement). For different time of experiment there was a significant difference in measured values. The discrepancy between values obtained in the different experiment repeated at different times was estimated as an absolute value of the difference between measured values. The value of discrepancy was marked in a form of bars in Fig. 7 and Fig. 8.

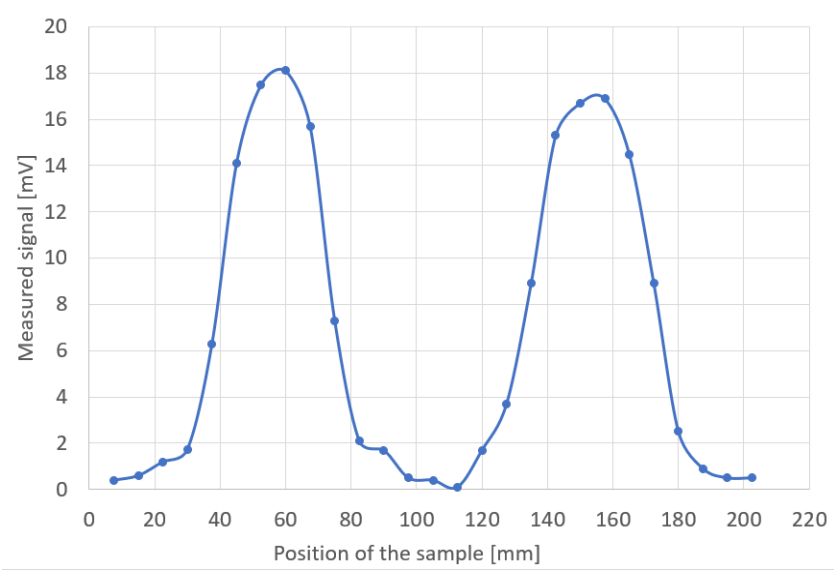

Fig. 6. Distribution of receive coils sensitivity along Z-axis. The value of induced voltage in receive coils in function of small sample position in the coils bore 


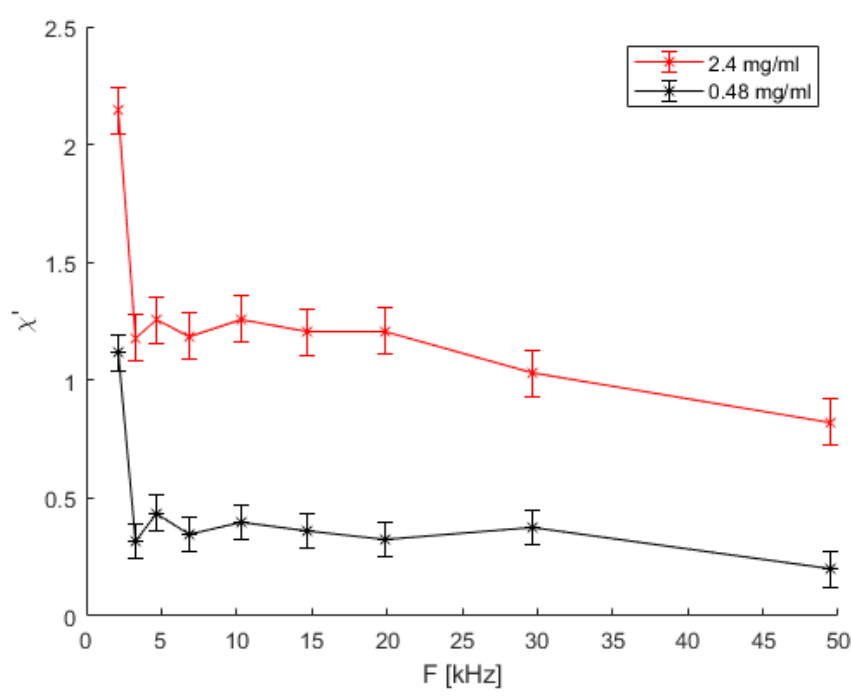

Fig. 7. Real part of magnetic susceptibility in function of excitation frequency. Measurements performed for 2 different concentrations of $20 \mathrm{~nm}$ nanomag-D-spio nanoparticles (Micromod Partikeltechnologie $\mathrm{GmbH}$ )

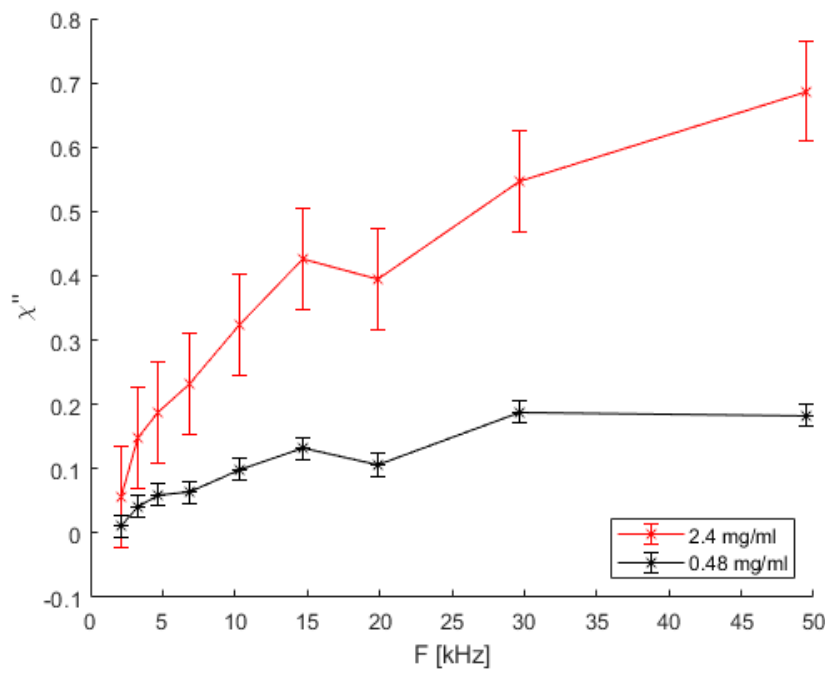

Fig. 8. Imaginary part of magnetic susceptibility in function of excitation frequency. Measurements performed for 2 different concentrations of $20 \mathrm{~nm}$ nanomag-D-spio nanoparticles (Micromod Partikeltechnologie GmbH)

\section{Conclusions}

The laboratory setup for AC impedance spectroscopy of magnetic nanoparticles was designed and built. The receiving coils were fabricated using 3D-printing. Flexibility of 3D-printing allowed us a rapid prototyping of designed carcass. Different material for carcass fabrication were tested. Though polycarbonate (PC) presented the highest maximum operating temperature $\left(121^{\circ} \mathrm{C}\right)$ we found that it was too fragile and crumbled during winding. Finally the carcass was made of Tough PLA with maximum working temperature $\left(63^{\circ} \mathrm{C}\right)$. Despite the low melting temperature the carcass was able to withstand heat losses generated by current induced due to alternating magnetic field of $1.8 \mathrm{mT}$.

The uniformity of magnetic field generated by excitation coil in the volume corresponding to the setup of receive coils was sufficient for measurements. Despite the applied configuration of receive coils the complete cancellation of excitation field has not been achieved but was lowered to an acceptable level of unbalance.

Applied symmetrical placement of reference coil in respect to detection coils resulted in the constant value of the phase-angle of the reference signal.
The first measurement using experimental setup was performed in limited frequency range from $2.2 \mathrm{kHz}$ to $50 \mathrm{kHz}$. Real and imaginary part of magnetic susceptibility in function of frequency obtained in our experiment present a similar characteristic as presented in the literature [1,7]. Measurements need to be performed in broader spectrum of frequencies for proper estimation of the frequency that maximizes magnetic losses for $20 \mathrm{~nm}$ nanomag-D-spio. Other methods such as calorimetric measurements of power losses are planned to be used to confirm the results obtained in the future experiments.

As expected we were able to measure smaller value of magnetic susceptibility for a sample of lower iron concentration. However, the ratio in measured magnetic susceptibility values between both samples was 3.5 in average and did not correspond exactly to iron content differences in prepared samples, which were designed to contain 5 times more iron in the first sample $(2.4 \mathrm{mg} / \mathrm{dl})$ compared to the second one $(0.48 \mathrm{mg} / \mathrm{dl})$. Other measurements should be made to verify if there is a linear response between measured value of magnetic susceptibility and iron concentration in the examined sample.

Using Lock-In amplifier it is possible to join AC magnetometry (spectrum of different excitation frequencies) with MPS method (spectrum of different harmonics for each excitation frequency). Further research need to be done to investigate combination of MPS-AC magnetometry.

\section{Acknowledgments}

This work was supported with grant number: 504/04558/1034/43.050003 awarded by Scientific Council for the Discipline of Biomedical Engineering (RND Inżynieria Biomedyczna) of Warsaw University of Technology.

\section{References}

[1] Bogren S. et al. Classification of Magnetic Nanoparticle Systems-Synthesis, Standardization and Analysis Methods in the NanoMag Project. International Journal of Molecular Sciences 16(9)/2015, 20308-20325 [http://doi.org/10.3390/ijms160920308].

[2] Graeser M. et al.: Analog receive signal processing for magnetic particle imaging. Med. Phys. 40(4)/2013, 042303 [http://doi.org/10.1118/1.4794482]

[3] Harabech M. et al.: The Effect of the Magnetic Nanoparticle's Size Dependence of the Relaxation Time Constant on the Specific Loss Power of Magnetic Nanoparticle Hyperthermia. Journal of Magnetism and Magnetic Materials 426/2017, 206-210 [http://doi.org/10.1016/j.jmmm.2016.11.079].

[4] Hergt R. et al.: Magnetic Particle Hyperthermia: Nanoparticle Magnetism and Materials Development for Cancer Therapy. Journal of Physics Condensed Matter 18(38)/2006, S2919 [http://doi.org/10.1088/0953-8984/18/38/S26].

[5] Kishore K., Akbar S. A.: Evolution of Lock-In Amplifier as Portable Senso Interface Platform: A Review. IEEE Sensors Journal 20(18)/2020, 10345-10354 [http://doi.org/10.1109/JSEN.2020.2993309].

[6] Ludwig F. et al.: Analysis of AC Susceptibility Spectra for the Characterization of Magnetic Nanoparticles. IEEE Transactions on Magnetics 53(11)/2017, 10 13 [http://doi.org/10.1109/TMAG.2017.2693420].

[7] Mahdavi Z. et al.: Core-Shell Nanoparticles Used in Drug DeliveryMicrofluidics: A Review. RSC Advances 10(31)/2020, 18280-18295 [http://doi.org/10.1039/d0ra01032d].

[8] Maity D., Ganeshlenin K.: Superparamagnetic Nanoparticles for Cance Hyperthermia Treatment. Nanotechnology Characterization Tools for Tissue Engineering and Medical Therapy, Springer Berlin Heidelberg, 2019, 299-332 [http://doi.org/10.1007/978-3-662-59596-1_7].

[9] Reeves D. B., Weaver J. B.: Magnetic Nanoparticle Sensing: Decoupling the Magnetization from the Excitation Field. Journal of Physics D: Applied Physics 47(4)/2013, 45002 [http://doi.org/10.1088/0022-3727/47/4/045002].

[10] Sandler S. E. et al.: Best Practices for Characterization of Magnetic Nanoparticles for Biomedical Applications. Analytical Chemistry 91(22)/2019, 14159-14169 [http://doi.org/10.1021/acs.analchem.9b03518].

[11] Šouc J. et al.: Calibration Free Method for Measurement of the AC Magnetization Loss. Superconductor Science and Technology 18(5)/2005, 592-595 [http://doi.org/10.1088/0953-2048/18/5/003].

[12] Suhaimi N. S. et al.: A Resonant Type AC Magnetometer for Evaluation of Magnetic Nanoparticles. Hassan M. (eds) Intelligent Manufacturing \& Mechatronics. Lecture Notes in Mechanical Engineering. Springer, Singapore 2018 [http://doi.org/10.1007/978-981-10-8788-2_9].

[13] Sun Y. et al.: An Improved Method for Estimating Core Size Distributions of Magnetic Nanoparticles via Magnetization Harmonics. Nanomaterials 10(9)/2020, 1-12 [http://doi.org/10.3390/nano10091623]. 
[14] Valentini M. et al.: Diffusion NMR Spectroscopy for the Characterization of the Size and Interactions of Colloidal Matter: The Case of Vesicles and Nanoparticles. Journal of the American Chemical Society 126(7)/2004, 2142-2147 [http://doi.org/10.1021/ja037247r].

[15] Vallejo-Fernandez G. et al.: Mechanisms of Hyperthermia in Magnetic Nanoparticles. Journal of Physics D: Applied Physics 46(31)/2013 [http://doi.org/10.1088/0022-3727/46/31/312001]

[16] Van De Loosdrecht M. M. et al.: A Novel Characterization Technique for Superparamagnetic Iron Oxide Nanoparticles: The Superparamagnetic Quantifier, Compared with Magnetic Particle Spectroscopy. Review of Scientific Instruments 90(2)/2019 [http://doi.org/10.1063/1.5039150].

\section{M.Sc. Eng. Mateusz Midura}

e-mail: M.Midura@ire.pw.edu.pl

Mateusz Midura was born in Rzeszów, Poland, in 1994. Received the M. Sc. degree from Warsaw University of Technology, Warsaw, Poland in 2019. $\mathrm{He}$ is Ph.D. student in the Nuclear and Medical Electronics Division, IriTM, Electronics and Information Technology Faculty, WUT and the last year student of medicine at Medical University of Warsaw, Faculty of Medicine. His field of interest covers Magnetic Particle Imagining, Magnetic Hyperthermia and position sensitive gamma ray detectors.

http://orcid.org/0000-0002-2449-0652

\section{M.Sc. Eng. Przemysław Wróblewsk}

e-mail: P.Wróblewski@ire.pw.edu.pl

Received the M. Sc. degree in biomedical engineering from Warsaw University of Technology, Warsaw, Poland in 2013. Ph.D. student in the Nuclear and Medical Electronics Division, IRiTM, Electronics and Information Technology Faculty, Warsaw University of Technology. His field of interest covers Magnetic Particles Imaging, Magnetic Hyperthermia and Magnetic Particles Spectroscopy, design of scanners and simulation of the magnetic field.

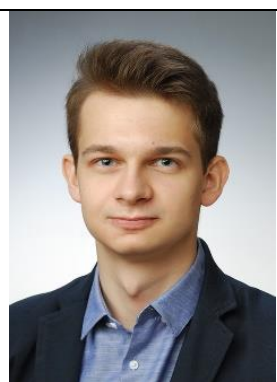

http://orcid.org/0000-0002-6713-9088

\section{M.Sc. Eng. Damian Wanta \\ e-mail: D.Wanta@ire.pw.edu.p}

Damian Wanta was born in Starogard Gdański, Poland, in 1991. He received the M. Sc. degree in biomedical engineering from Warsaw University of Technology, Warsaw, Poland in 2016. He is Ph.D student in the Nuclear and Medical Electronics Division, IRiTM, Electronics and Information Technology Faculty, WUT. His current research interests include Imaging of Magnetic Nanoparticles, Electrical Capacitance Tomography and Partial Reconfiguration.

http://orcid.org/0000-0002-1596-6524
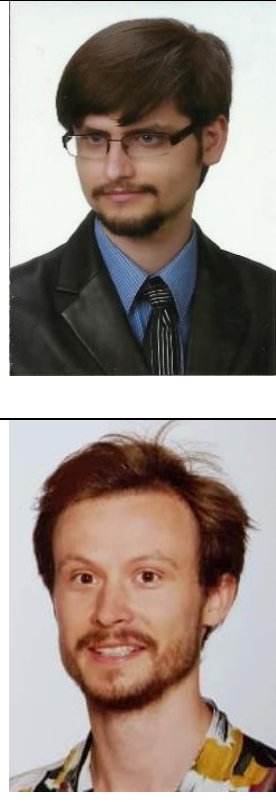

[17] Wróblewski P., Smolik W.: Coil design with litze wire for magnetic particle spectrometry. Informatyka, Automatyka, Pomiary w Gospodarce i Ochronie Środowiska 7(1)/2017, 150-153 [http://doi.org/10.5604/01.3001.0010.4605].

[18] Wu K. et al.: Magnetic Particle Spectroscopy: A Short Review of Applications Using Magnetic Nanoparticles. ACS Applied Nano Materials 3(6)/2020, 497289 [http://doi.org/10.1021/acsanm.0c00890].

[19] Yang T. Q. et al.: Detection of Magnetic Nanoparticles with Ac Susceptibility Measurement. Physica C: Superconductivity and Its Applications 412414/2004, 1496-1500 [http://doi.org/10.1016/j.physc.2004.01.146].

[20] Quantum Design, MPMS Application Note 1070-207: Using PPMS Superconducting Magnets at Low Fields 2009.

\section{Ph.D. Eng. Grzegorz Domański}

e-mail: G.Domanski@ire.pw.edu.p

Received M.Sc. degree and the Ph.D. degree from Warsaw University of Technology, Warsaw, Polan in 1994 and 2001, respectively. Senior lecturer in the Nuclear and Medical Electronics Division, IRiTM, Electronics and Information Technology Faculty, WUT Secretary of Warsaw branch of The Polish Society of Medical Physics (2001 2005). Deputy director for radiological protection affairs since 2001. His main research interests are biocybernetics and biomedical engineering.

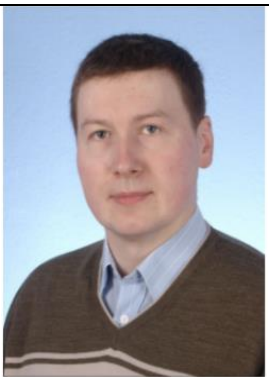

http://orcid.org/0000-0002-0204-2322

\section{M.Sc. Eng. Mateusz Stosio
e-mail: M.Stosio@ire.pw.edu.pl}

Mateusz Stosio was born in Mińsk Mazowiecki, Poland, in 1989. He received the M.Sc. degree in electronics and computer engineering from the Warsaw University of Technology, Warsaw, in 2014. He is currently pursuing Ph.D. degree with the Division of Nuclear and Medical Electronics, Faculty of Electronics and Information Technology, Institute of Radioelectronics and Multimedia Technology. His research interests include impedance measurement and Electrical Capacitance Tomography. http://orcid.org/0000-0002-7488-1969

\section{Ph.D. Eng. Jacek Kryszyn
e-mail: J.Kryszyn@ ire.pw.edu.p}

Jacek Kryszyn was born in Warsaw, Poland, in 1986. $\mathrm{He}$ received his M.Sc. degree in electronics and computer engineering and the Ph.D. degree from Warsaw University of Technology, Warsaw, Poland in 2012 and 2018, respectively. He is an assistant professor at the IRiTM, Electronics and Information Technology Faculty, WUT since 2019. His field of interest covers Electrical Capacitance Tomography, especially small capacitance measurement methods.

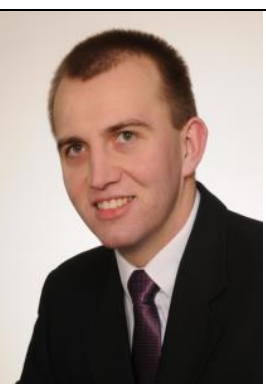

http://orcid.org/0000-0002-0042-0473

\section{Prof. Waldemar T. Smolik}

e-mail:W.Smolik@ire.pw.edu.pl

Waldemar T. Smolik was born in Otwock, Poland, in 1966. He received the M.Sc., the Ph.D. and D.Sc. degrees in electronics engineering from Warsaw University of Technology, Warsaw, Poland in 1991 , 1997 and 2014, respectively.

Since 2016, he is a Professor at the Institute of Radioelectronics and Multimedia Technology, Electronics and Information Technology Faculty, WUT. He is the head of the Laboratory of Dat Acquisition and Processing Systems at the Division of Nuclear and Medical Electronics.

http://orcid.org/0000-0002-1524-5049

otrzymano/received: $29.01 .2021 \quad$ przyjęto do druku/accepted: 15.03 .2021 